\title{
Modeling of Micro-grid with the consideration of total harmonic distortion analysis
}

\author{
Ibrahim Alhamrouni ${ }^{1}$, Wira Wahab ${ }^{2}$, Mohamed Salem ${ }^{3}$, Nadia H. A. Rahman ${ }^{4}$, Lili Awalin \\ ${ }_{1,2,4,5}$ Electrical Engineering Section, University Kuala Lumpur (UniKL BMI), Malaysia \\ ${ }^{3}$ School of Electrical and Electronic Engineering, Universiti Sains Malaysia, Malaysia
}

\begin{abstract}
Article Info
Article history:

Received Oct 16, 2018

Revised Feb 18, 2019

Accepted Mar 4, 2019

\section{Keywords:}

Grid-connected mode

Islanded mode

Machine Micro-grid

Photovoltaic(PV)

Total harmonic distortion

(THD)

Wind turbine generation(WTG)

ABSTRACT

With the rapid expansion of electricity grid, there yet still places to be covered considering their remote location. Micro-grid (MG) is a solution in this scenario, in fact, there is actually many cases where MG is used in case of emergency and act as a backup to the main electrical grid. By disconnecting itself from the larger grid, a grid that can have many problems, the micro-grid becomes much more flexible in its operations and by continuing to power households and communities alike. Besides grid-connected mode, it is necessary for the MG to operate in autonomous mode. By operating in islanded mode, micro-grids must be able to supply critical load without interruption, run at specific values for voltage and power and extract the maximum power from the distributed generations (DG). Therefore, the modeling of microgrid network considering solar photovoltaic (PV) and wind turbine generation (WTG) system as the distributed generation have been modeled using Matlab/Simulink in this research. Apart from that, the observation of total harmonic distortion (THD) between two operation modes of grid-connected and the islanded-mode is presented in order to analyze the power quality stability towards two operations MG network with same loads size and network parameters.
\end{abstract}

Copyright $@ 2019$ Institute of Advanced Engineering and Science. All rights reserved.

\section{Corresponding Author:}

Ibrahim Alhamrouni,

Electrical Engineering Section,

University Kuala Lumpur (UniKL BMI),

Gombak 53100, Malaysia.

Email: ibrahim.mohamed@unikl.edu.my

\section{INTRODUCTION}

Micro-grid (MG) is a localized group of electricity generation, energy storage, and loads that normally operated through a connection to a centralized grid [1]. However, DG sources have limitations in term of energy generation capacity. In order to increase the power quality and reliability in the MG system, it is shown in the process of combining the source of the micro-source (MS) such as solar and wind. Plus, the system behavior during transfer mode from grid connected to islanded mode MG [2].

Typically, the use of renewable energy sources such as solar power, wind power, and others are the reason why the installation of DG's are highly recommended in power generation technology. Use of DG source however will protect our nature because its containing low harmful emission leads to natural disaster. The harmonic effect gives a high impact on the system. It can be harmful to end user equipment's because of the overheating etc. It also can be misfiring meter reading and disturb the efficiency of the power grid, power distribution and power generation [4]. In power system, harmonic can effect the transformer because harmonic can produce additional losses in transformer core.

In $\mathrm{MG}$, the system generates locally to reduce dependence on long transmission lines and cut transmission losses. In peak loads, it prevents utility grid failure by reducing the load on the grid. Significant environmental benefits made possible by the use of low or zero emission generators [5]. The use of both 
electricity and heat permitted by the close proximity of the generator to the user, thereby increasing the overall efficiency at the same time, reduces electricity cost to the user. Therefore, this work concerns about the analysis on the total harmonic distortion (THD) between both modes to make full use of their advantages and planning for suitable harmonic mitigation technique.

\section{PROPOSED SYSTEM CONFIGURATION}

From Figure 1, it has been shown that the loads receive energy from two types of different sources, which is from utility supply, and another one from the DGs. During the case of grid connected, the loads will operate according to the utility supply and vice versa, when the network required operating on islanded mode the loads will operate according to the DGs.

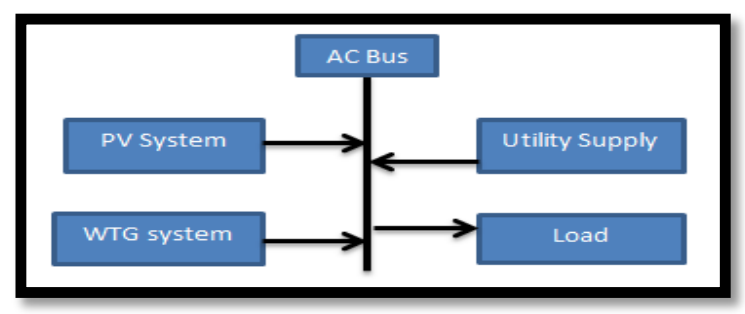

Figure1. M-G proposed system block diagram

\subsection{Solar PV System Configuration}

PV system is the method of converting solar energy into direct current electricity using semiconductor materials which exhibit photovoltaic effect. PV model represent solar irradiance and temperature changes. The implementation of PV array is built of strings of PV modules connected in parallel. The block diagram of the proposed research is illustrated in the Figure 2.

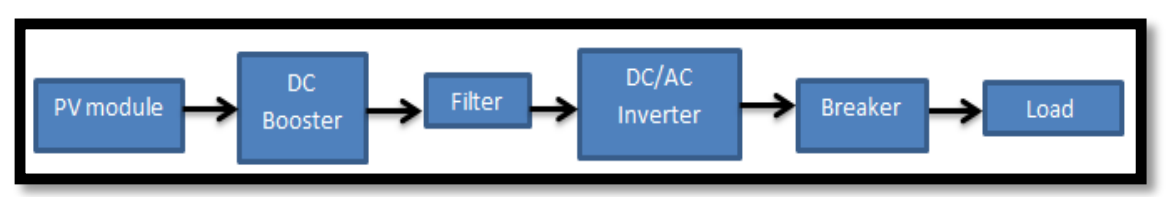

Figure 2. Solar PV system block diagram

\subsection{WTG System Configuration}

The wind is made up of real matter with mass, when mass is moving it has kinetic energy. Wind turbines work by turning the kinetic energy of the wind into torque (a force) that causes the wind turbine to turn and drives an electrical generator. The proposed WTG system block diagram is demonstrated in Figure 3.

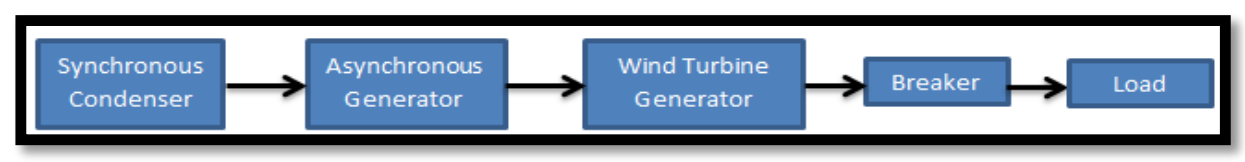

Figure 3. WTG proposed system block diagram

\section{SIMULATION}

By using Matlab/Simulink, the simulation is executed with five seconds sample time with 50 microseconds discrete powergui block function. Figure 4 shows the design of the first operation mode (grid connected mode), in order to investigate the implementation process of energy reliable power system. Efficient micro-grid network is required to operate smoothly in both standalone and grid-connected modes. By using the renewable energy as a source of the generation system, that has forced the MG to include the 
power electronic devices such as DC-DC Booster, DC-AC inverter, Load Frequency Regulator and suitable simple component control technique with some default existing parameters from previous study. Grid-connected DG micro-grid network is shown in Figure 4. Process of tuning parameters is the challenge in this simulation due to the effect of the low resistance and high sensitivity of the electronic parts. FFT Analysis is the case study proposed to measure the total harmonic distortion on the MG system that will show the different of the performance between two MG modes towards same network and load behavior.

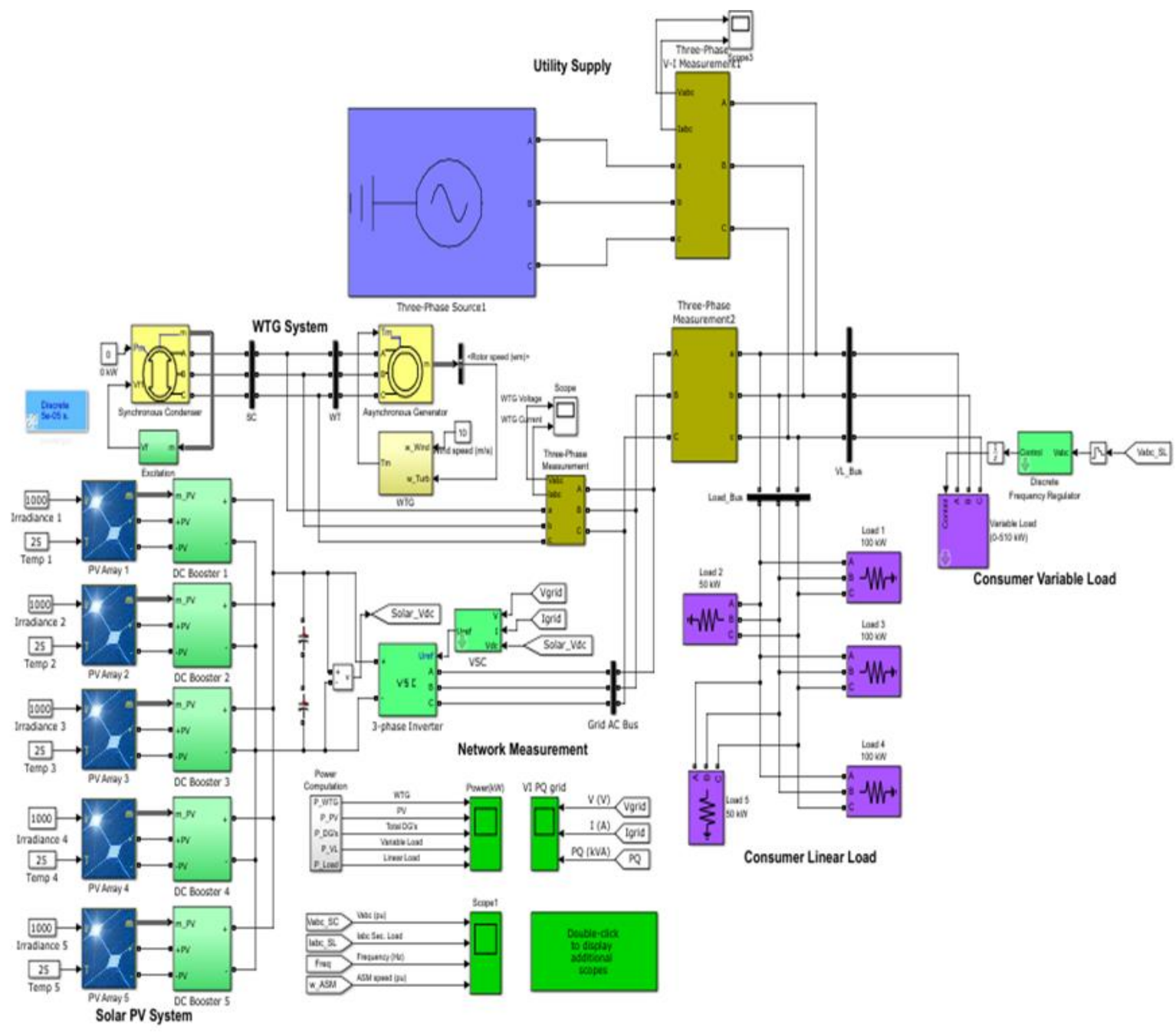

Figure 4. Grid-connected DG micro-grid network

\subsection{Grid-Connected Mode}

As for the design of grid-connected mode, the total connected loads are relying on the supply from utility source. By implementing the supply from the utility, all the possible ways of power quality improvement method have been applied. Even the real life variable load, the power quality issues can be mitigated and minimized according to specific standards. Grid-connected mode M-G circuit diagram is shown in Figure 5. Grid-connected mode is used in order to enhance the generated power in the network in order to counter in the issue of energy deficiency from the distributed generations supply.

\subsection{Islanded Mode}

Figure 6 shows the MG islanded-mode circuit diagram. As for the modelling of micro-grid in islanded-mode, the electricity is generated from inexhaustible and replenished sources interconnected via voltage source converters (VSC). The output of voltage magnitude and phase are controlled by using VSC in PV model. This is correlated to the synchronous machine based on the wind turbine generation, where the voltage magnitude and the rate-of change of the generator angle (frequency) is set as a result of the

\footnotetext{
Modeling of Micro-grid with the consideration of total harmonic distortion analysis (Ibrahim Alhamrouni)
} 
interaction between the generation and dynamic load. The output voltage magnitude and angle without VSC control will result in unplanned generation levels and voltage profiles in the micro-grid.

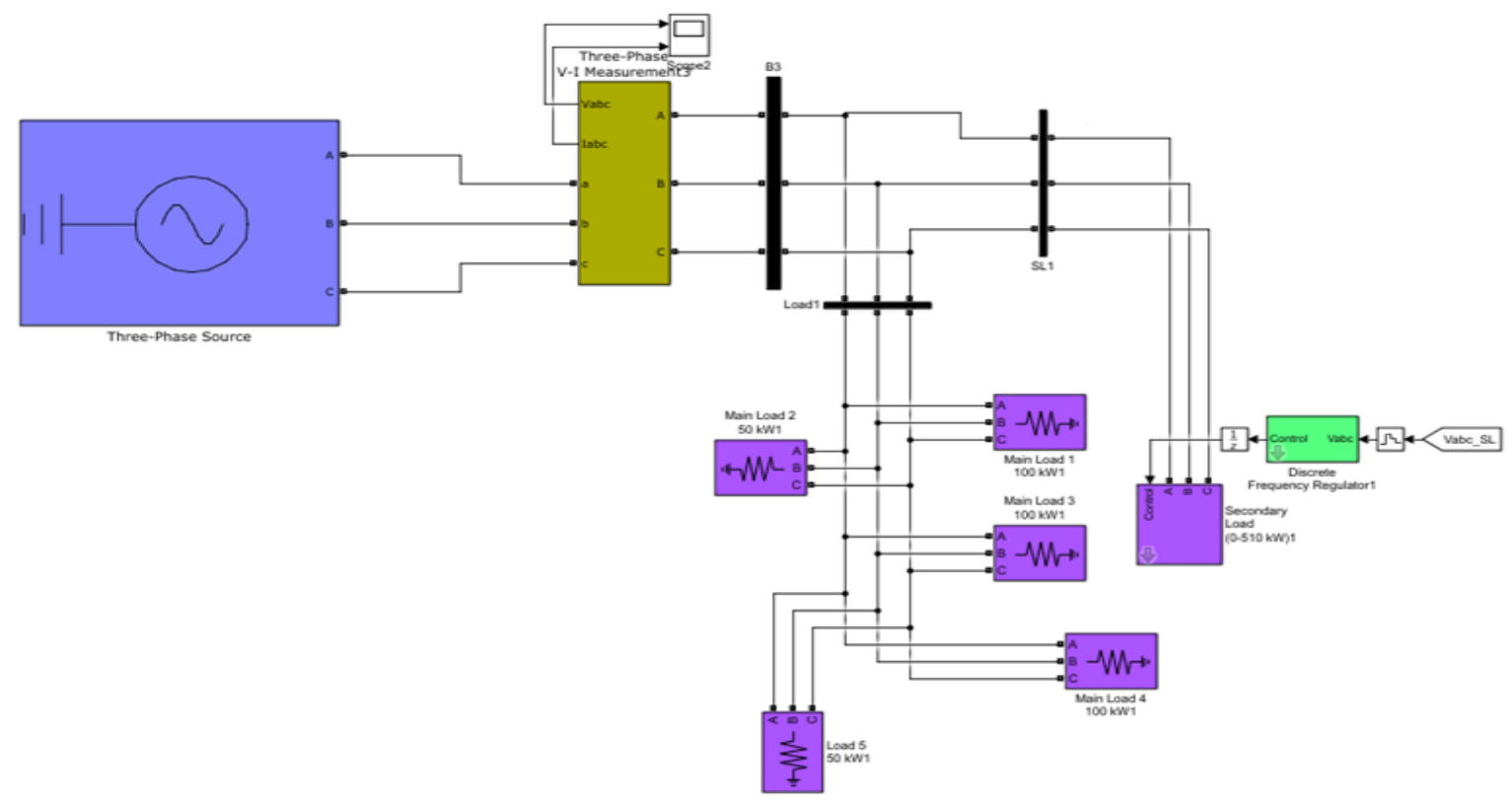

Figure 5. Grid-connected mode MG circuit diagram

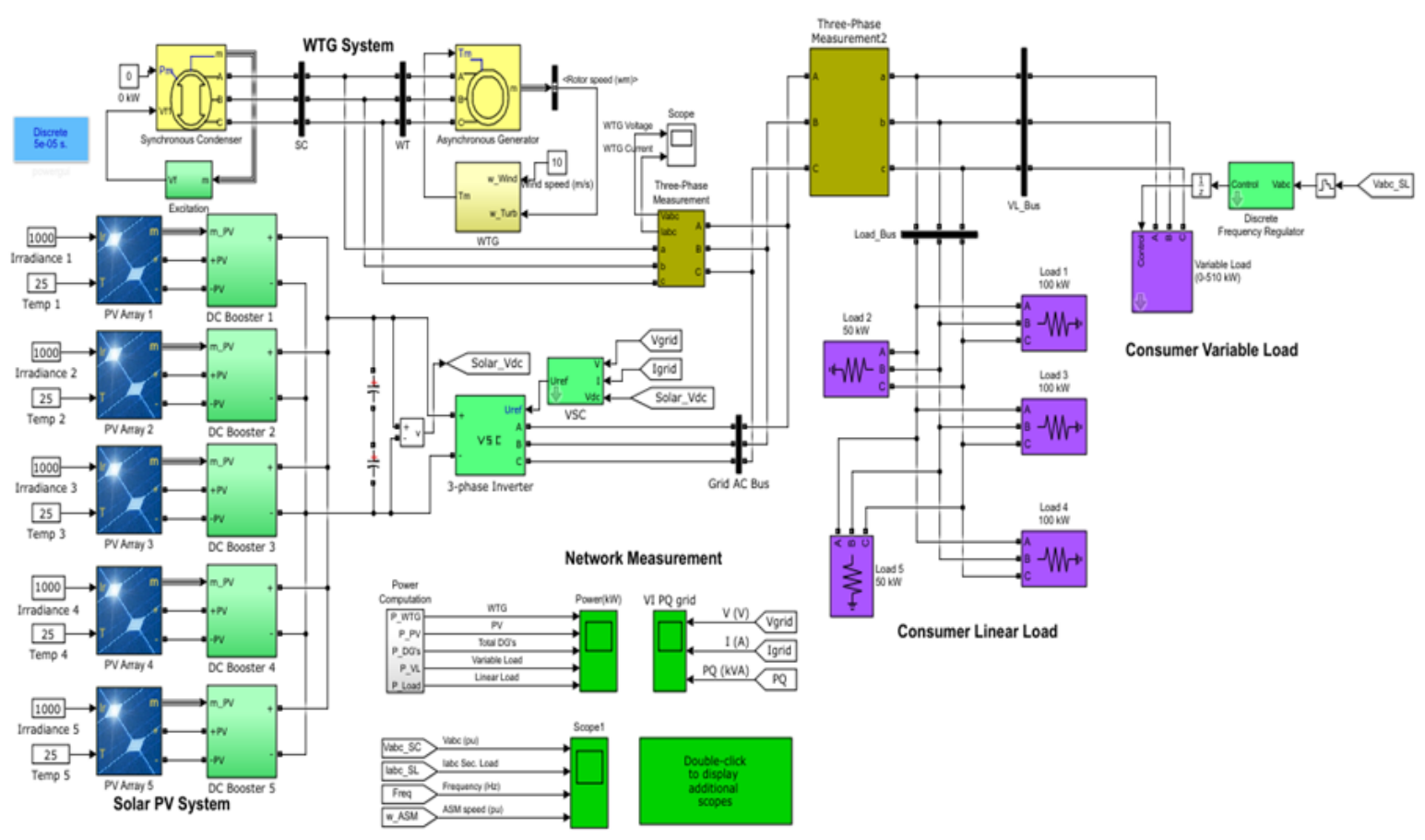

Figure 6. Islanded-mode MG circuit diagram

\subsubsection{Solar PV Model Parameters}

Each string consists of modules connected in series. Five SunPower SPR-315E-WHT-D types of PV modules are connected in parallel with the same parameter of 64 parallel strings and five series-connected modules per string. $1000 \mathrm{~W} / \mathrm{m}^{2}$ of sun irradiance and 25 degrees Celsius of temperature is the input for each 
unit that operates on 96 numbers of cells per module (as shown in Figure 7), maximum power for each module is 315.072 Watt. Open circuit voltage (Voc) and short circuit current $\left(\mathrm{I}_{\mathrm{sc}}\right.$ ) is set to 64.6V and 6.14A. Besides that, voltage and current at maximum power point is set to $54.7 \mathrm{~V}$ and $5.76 \mathrm{~A}$. DC booster consists of $100 \mu \mathrm{F}, 260 \mathrm{~V}$ initial voltage capacitor is connected in parallel with series filter of $0.005 \Omega$ resistor and $5 \mathrm{mH}$ inductor are used in order to boost DC voltage generated by solar panel. Next, the boosted DC voltage is transferred to the two units of $100 \mathrm{mF}$ c-filter in order to generate smoother DC volts. DC/AC inverter with existing VSC control is used to invert AC voltage and supply to the load demand. Since solar PV system depends on solar irradiant and temperature, the equation between solar panel current and voltage characteristic can be expressed as:

$$
I=I_{p h}-I_{o}\left(e^{\frac{q(V+I R s)}{n k T}}-1\right)-\frac{V_{-} I R s}{R_{s h}}
$$

Where $I_{p h}$ is the photocurrent, $I_{o}$ is the saturation current of the diode, $R s$ is the series resistance, $R_{s h}$ is the shunt resistance, $\mathrm{n}$ is the diode ideality factor, $k$ is Boltzmann's constant $(1.4 \times 10-23), q$ is the electron charge $(1.6 \times 10-19)$, while $T$ is the absolute temperature in Kelvin.

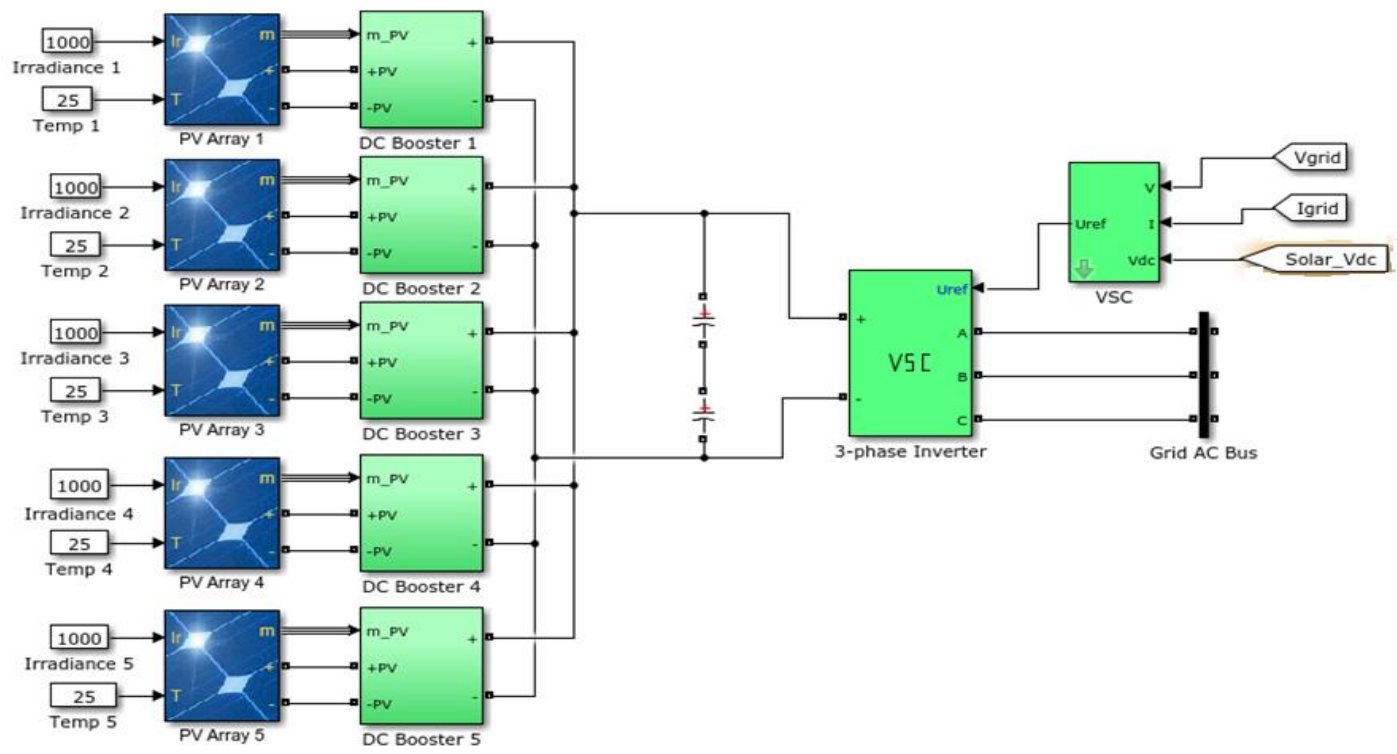

Figure 7. Matlab/simulink model of PV solar system

\subsubsection{WTG Model Parameters}

Figure 8 shows the Matlab Simulink model of WTG system. The process of WTG starts with the synchronous machine with existing parameter of 550kVA nominal power, 415 line-to-line voltage and $50 \mathrm{~Hz}$ frequency. Stator windings are connected in wye to an internal neutral point. Output from the synchronous machine is transfer to the asynchronous generator with same existing parameter to the synchronous machine since both components are used as the input to the wind turbine generator. Wind and rotor speed are set up to $10 \mathrm{~m} / \mathrm{s}$ and $1800 \mathrm{rpm}$ respectively, in order to generate sufficient power to the load.

\section{RESULTS AND DISCUSSION}

Analysis of the output voltage and current is performed in order to determine the difference between both case studies that using different kind of sources to supply the same network connection and load size.

\subsection{Grid Connected Mode}

Voltage and current of the grid-connected mode have been measured as shown in Figure 9. Since all possible suitable parameters have been set from the utility company, this system is able to produce 340Volts clean phase maximum voltage (Vmax/phase) and supply of 885 Amps of electricity to the size of 910kWatt total connected load. 


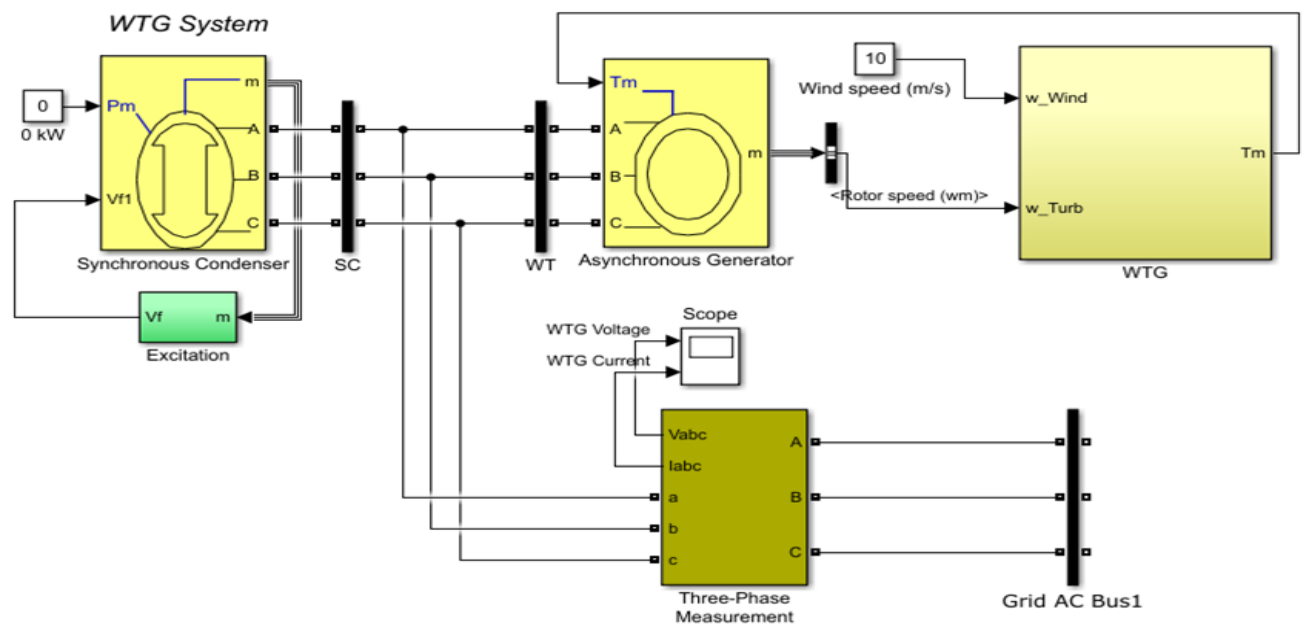

Figure 8. Matlab simulink model of WTG system

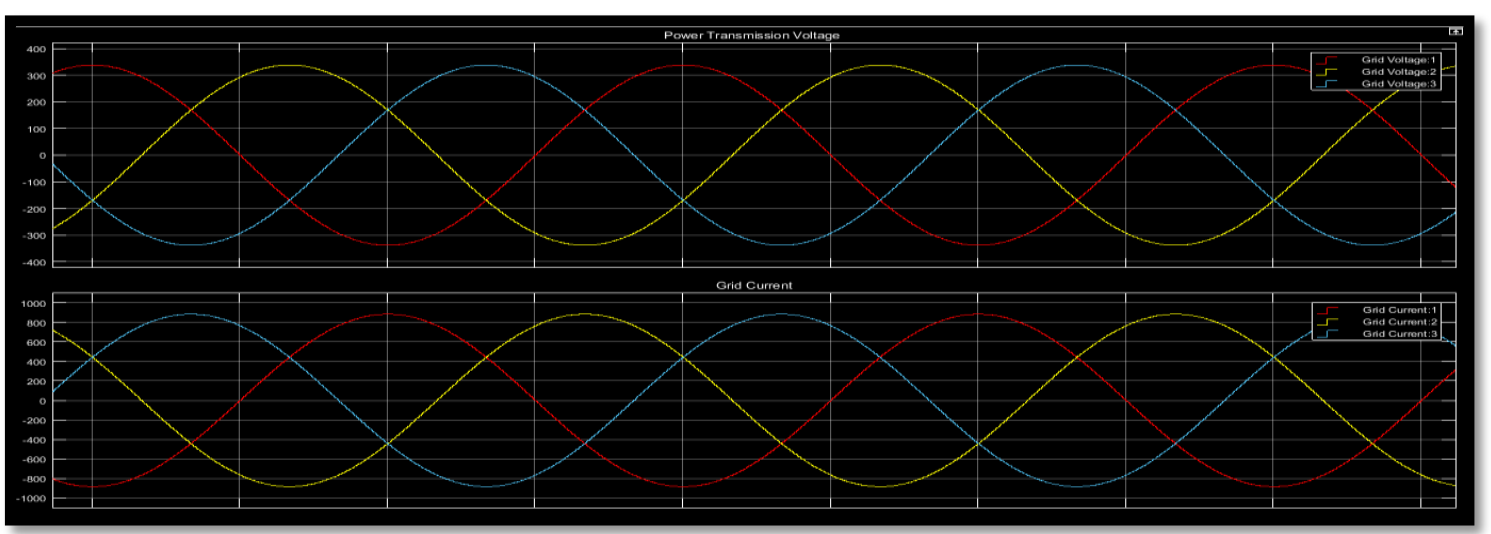

Figure 9. V and I characteristics of grid-connected mode

\subsection{Islanded Mode Micro-Grid}

The characteristic of V and I of the DG in islanded M-G mode is demonstrated in Figure 10. Voltage and current of the grid-connected mode have been measured as shown Figure 10 above. The simulation result initiate that the output voltage is $351 \mathrm{~V}$ while the output current is $917.2 \mathrm{~A}$ to the size of 910kWatt total connected load.

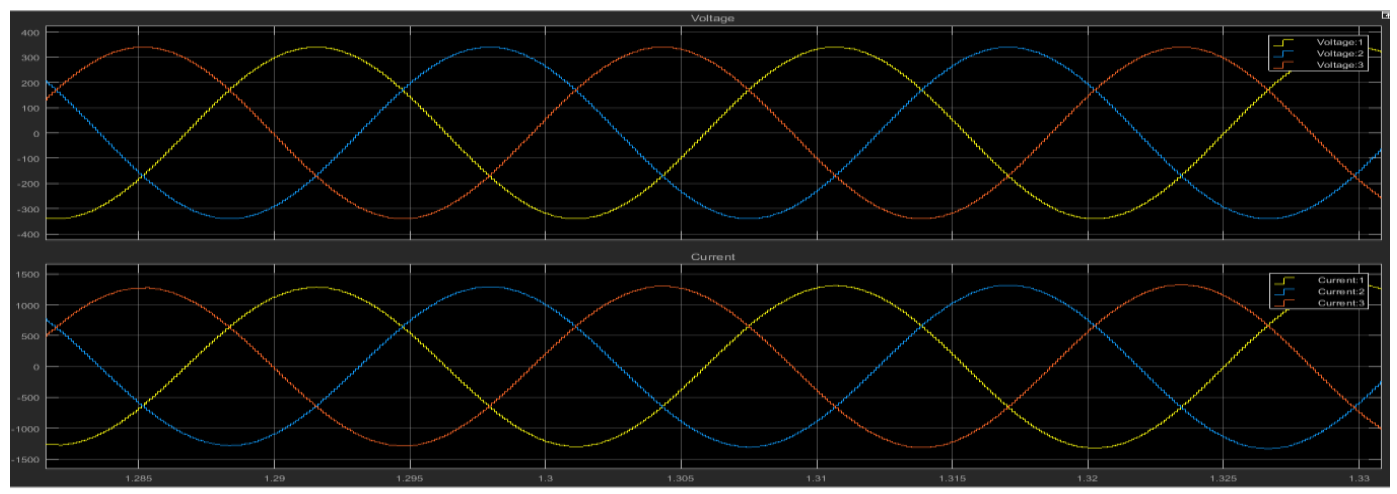

Figure 10. V and I characteristics of DG in islanded MG mode 
Voltage and current of wind turbine generation has been measured as illustrated in Figure 11. From the simulation, it can be analyzed that the wind turbine generator able to produce $341 \mathrm{~V}$ while the output current is $416 \mathrm{~A}$.

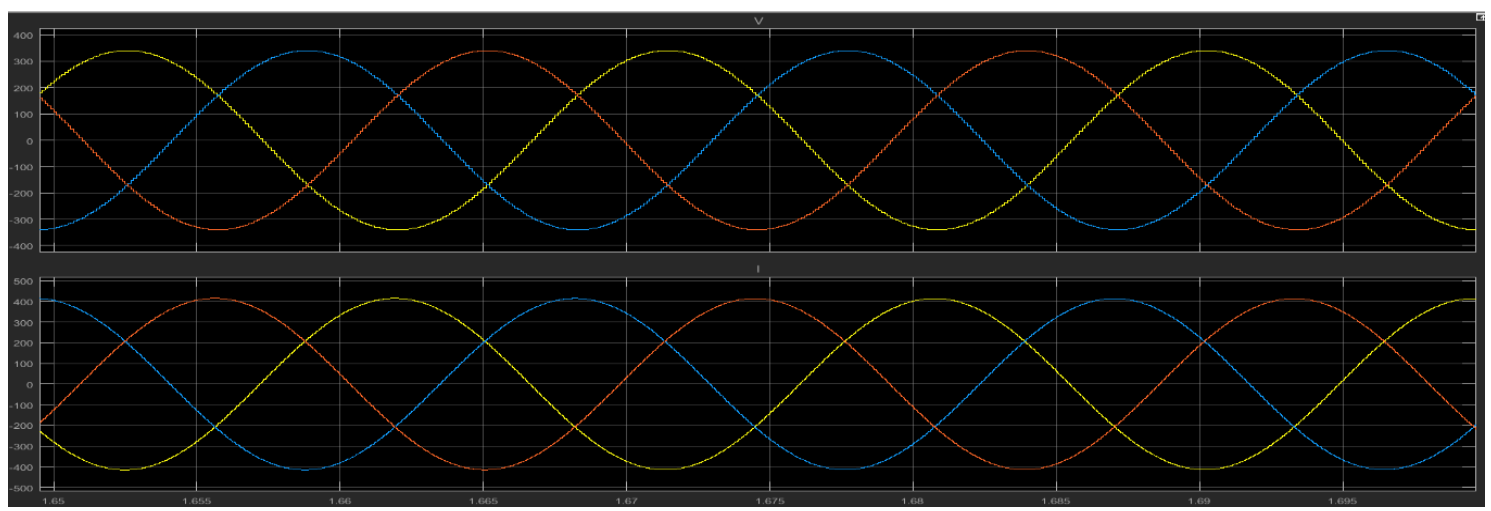

Figure 11. V and I characteristics of WTG

Voltage and current of the PV system have been measured as in Figure 12. Since the output from solar PV is in DC, so the output produced from the above Figure is the output after the inverter. The simulation indicates that the PV system is able to produce $340 \mathrm{~V}$ and $980 \mathrm{~A}$ of AC output.

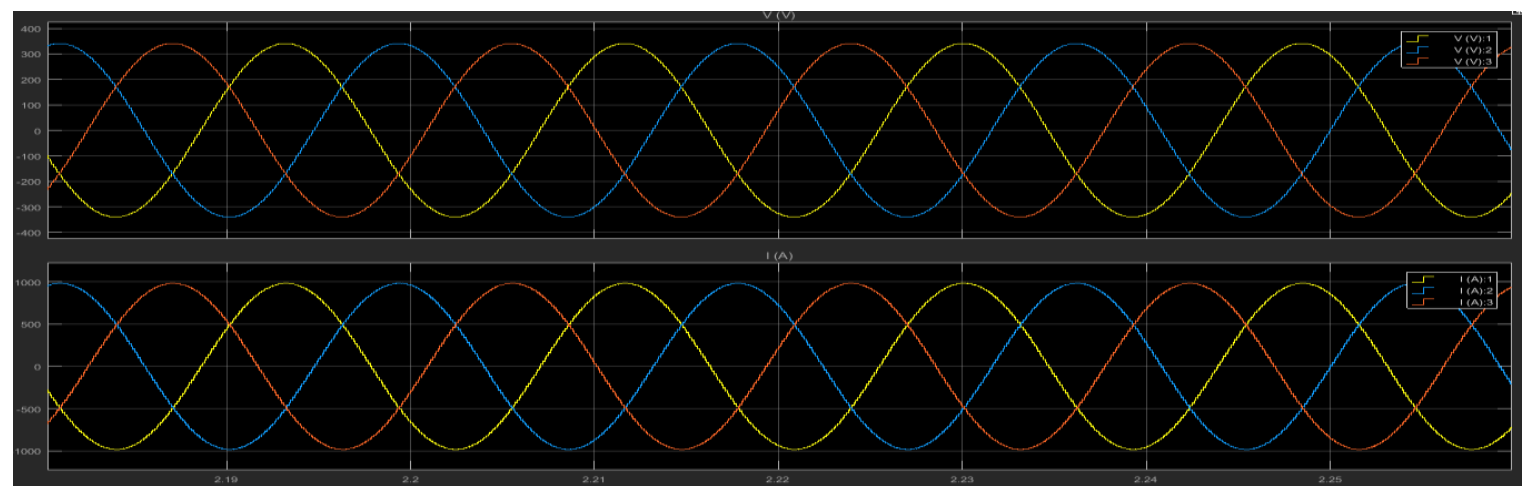

Figure 12. V and I characteristics of Solar PV

By using the reference voltage and current of each critical component such as WTG system, PV system, variable load and static loads in the Figure 13, power generated by DG's and absorbed power by the loads is observed in Figure 13. The pattern of total DG in the system is affected by the behavior of the load change as we can see at the time 0.9 seconds on the simulation result above. Active power reference of islanded-mode mg value as shown in Table 1.

Table 1. Active Power Reference of Islanded-Mode MG Value

\begin{tabular}{cc}
\hline M-G Component & Active Power \\
\hline WTG system & $383 \mathrm{~kW}$ \\
PV system & $511 \mathrm{~kW}$ \\
Total DG & $892 \mathrm{~kW}$ \\
Variable load & $405 \mathrm{~kW}$ (steady state) \\
Linear loads & $454 \mathrm{~kW}$ \\
\hline
\end{tabular}




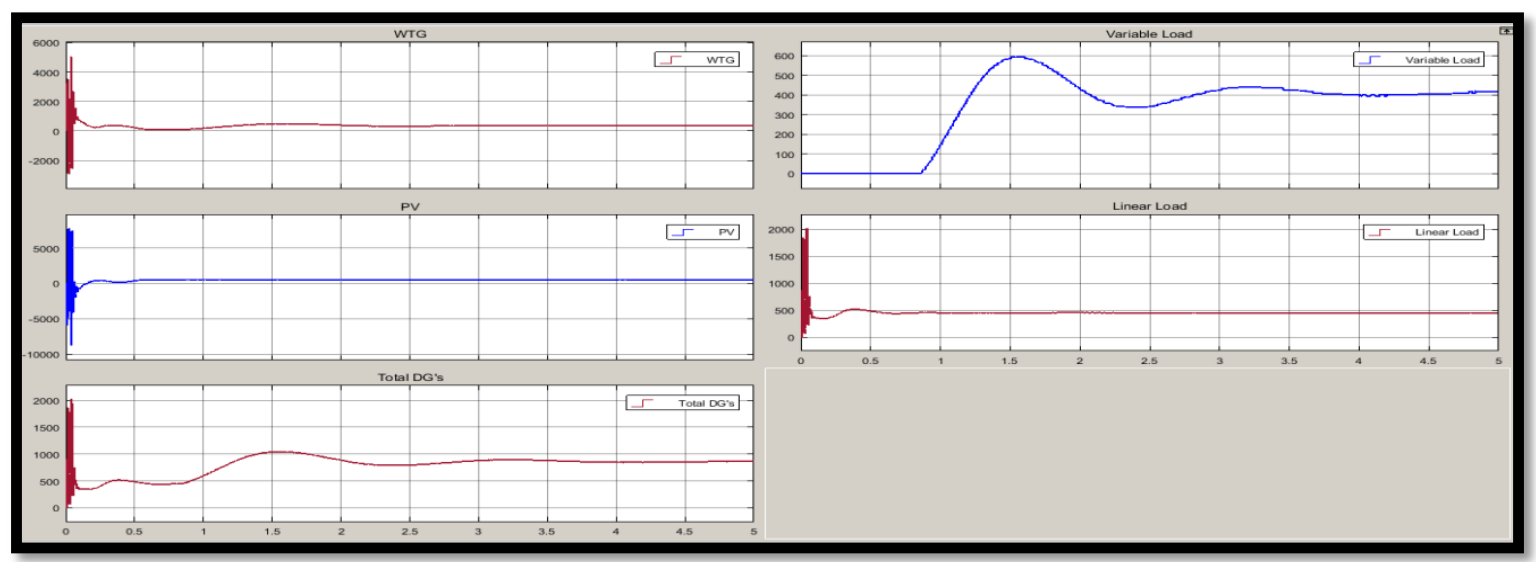

Figure 13. Active power reference of islanded-mode MG

\subsection{THD Analysis Using FFT Analyzer}

The THD analysis is conducted by using FFT analyzer. As we grasp, total harmonic distortion became a vital issue in power system as it should be aside as low as possible to comply with the international standard. In power system, lower THD lead to higher power factor while lowering the electricity bills hence resulting in higher efficiency. The aim of this analysis is to determine the harmonic distortion exist in this systems. Based on figure below, THD analysis for grid connected mode shows that there is no harmonic exist in the system as it not containing the power electronic components.

\subsubsection{Grid Connected Mode}

Signal magnitude of output voltage for grid connected mode as shown is Figure 14 As mentioned above, there is absence of harmonic distortion in grid connected mode, so the frequency spectrum as shown in Figure 15 which displays the fundamental voltage which is $338.8 \mathrm{~V}$.

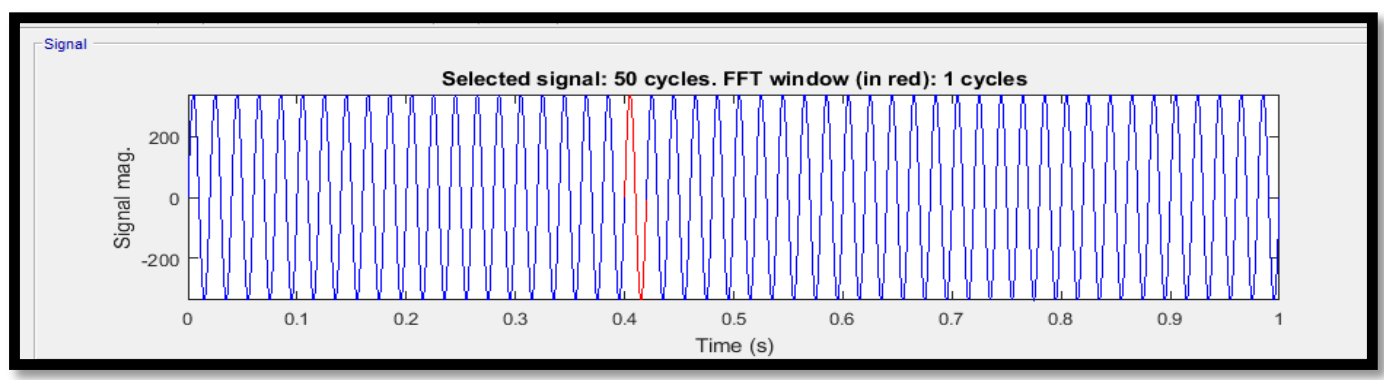

Figure 14. Signal magnitude of output voltage for grid connected mode

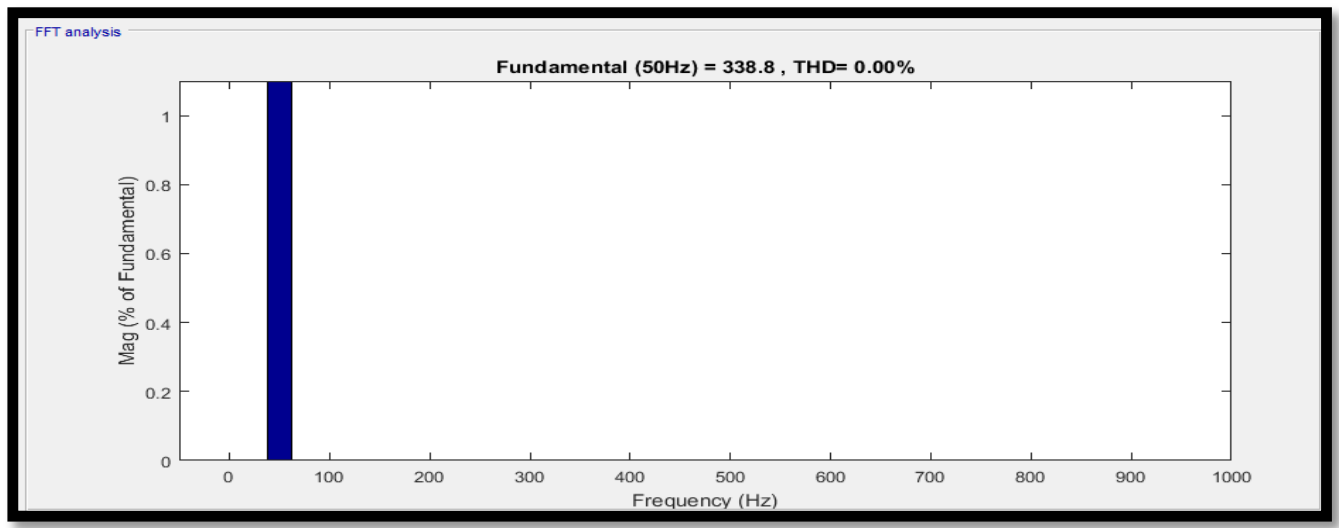

Figure 15. Frequency spectrum of output voltage for grid connected 
Figure 16 indicates that the output current for the grid connected mode is $885.4 \mathrm{~A}$ with $0.00 \%$ THD. Frequency spectrum of output current for grid connected as shown in Figure 17.

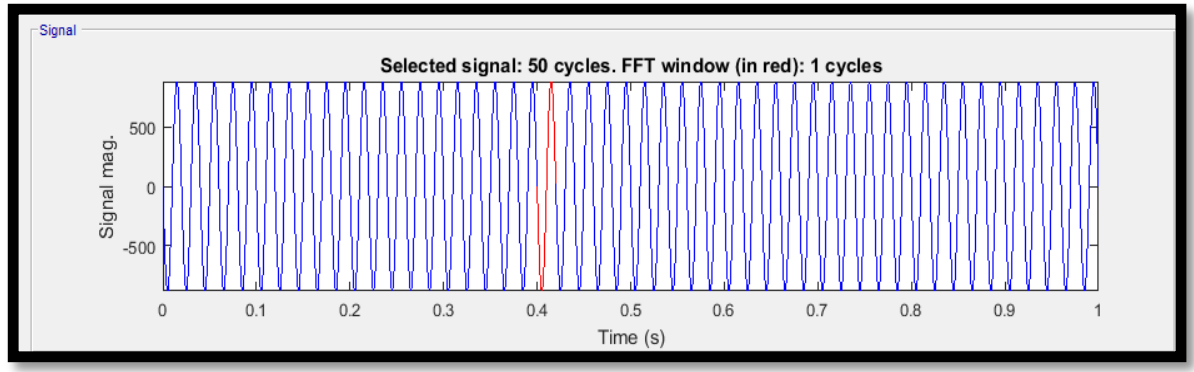

Figure16. Signal magnitude of output current for grid connected

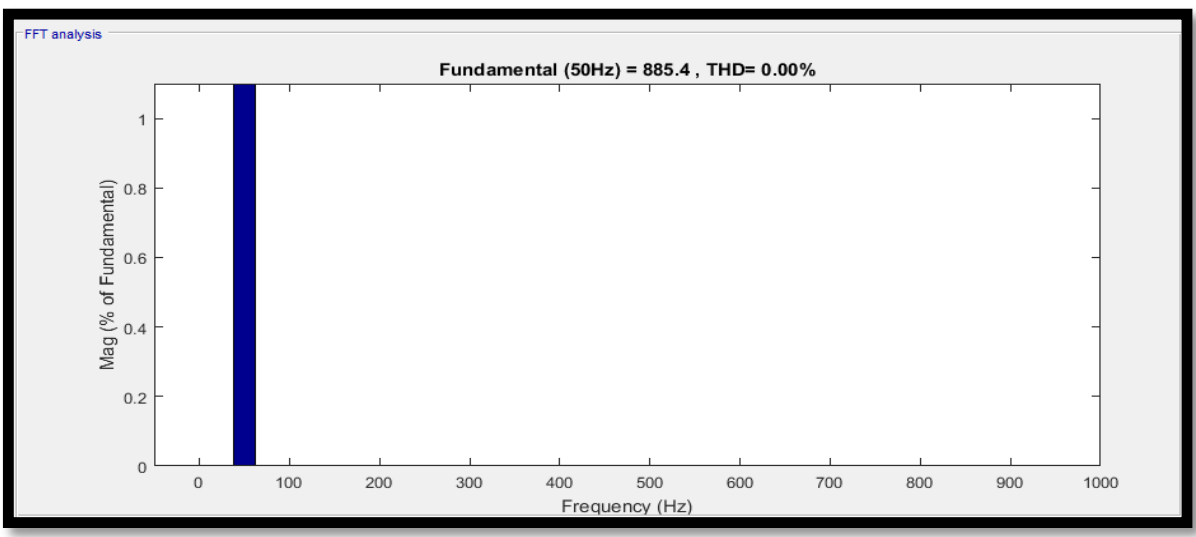

Figure 17. Frequency spectrum of output current for grid connected

According to the case presented above, there is no harmonic detected due to the supply system is provided by utility side plus the stability of loads support the system performance stability.

\subsubsection{Islanded Mode}

As for the islanded mode, there are existing of power electronic switches such as the IGBT and diode. These power electronic switches used in DC-DC booster to boost the output current and voltage and inverter to convert the DC input from PV to AC output. This power electronic is known as non-linear load where this type of load created the harmonic distortion as in [6, 7 and 8]. Signal magnitude of output voltage for islanded mode as shown is Figure 18.

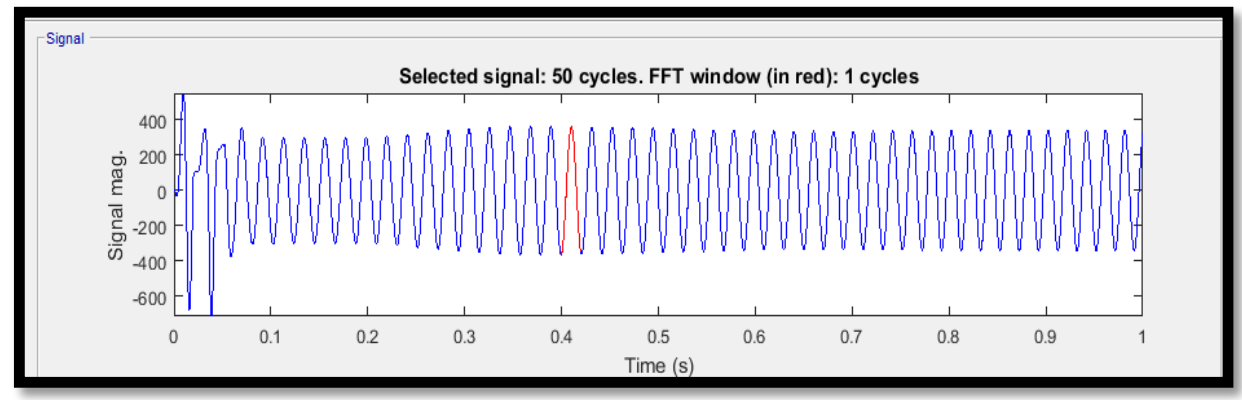

Figure 18. Signal magnitude of output voltage for islanded mode 
Figure 19 demonstrates the signal magnitude of output voltage and its frequency spectrum. Based on the simulation, it can be analyzed that the fundamental of output voltage for the islanded mode is $351 \mathrm{~V}$ with $3.80 \%$ total harmonic distortion. Signal magnitude of output current for islanded mode as shown is Figure 20. Figure 21 exhibit that the output current for this system is $917.2 \mathrm{~A}$ with $3.80 \%$ total harmonic distortion.

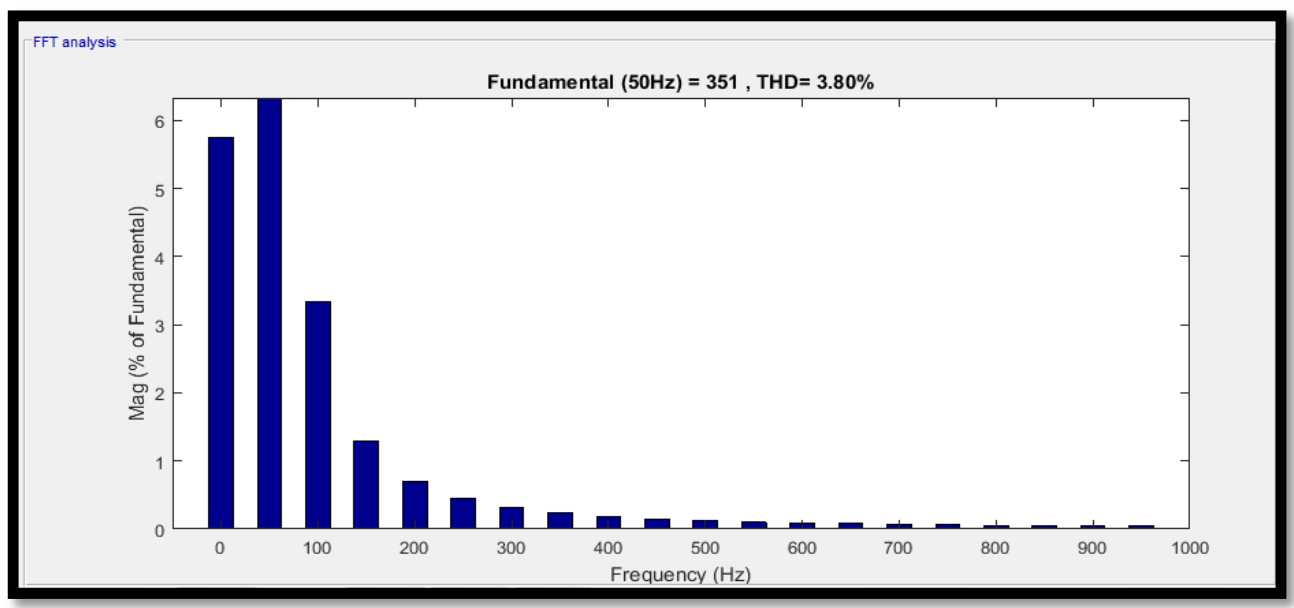

Figure 19. Frequency spectrum of output voltage for islanded mode

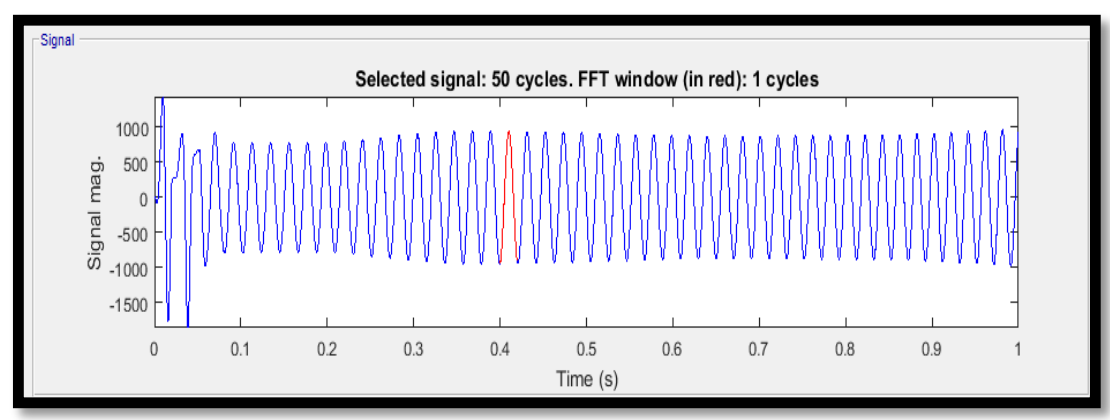

Figure 20. Signal magnitude of output current for islanded mode

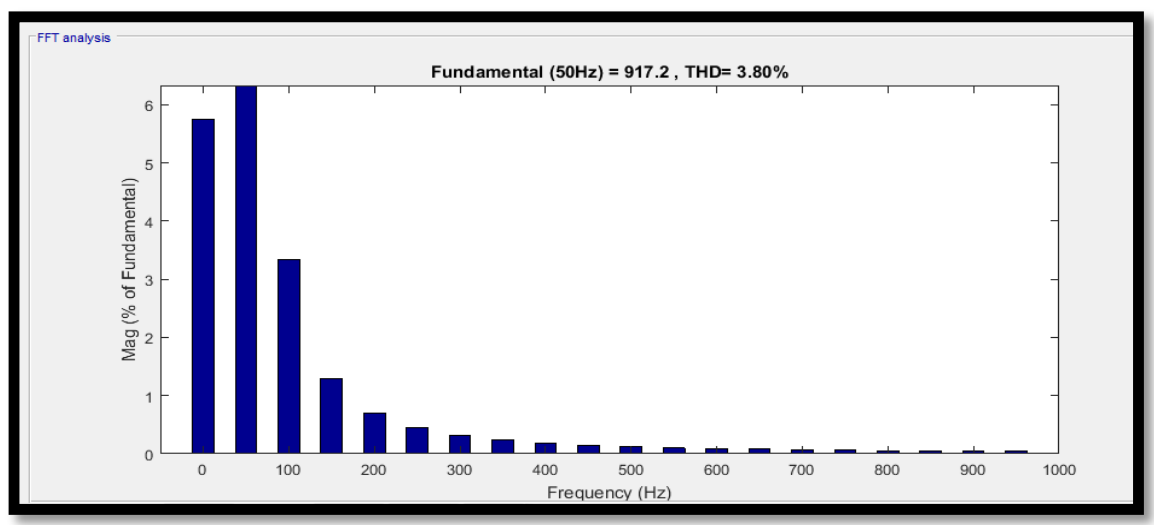

Figure 21. Frequency spectrum of output current for islanded mode

\section{RESULTS DISCUSSION}

The main focus of this work is modelling the micro-grid in its both operation modes (islanded and grid connected mode). Also, to ensure the power quality standards are met, total harmonic distortion analysis has been carried out. From the previous sections, it can be clearly seen that, micro-grid modelling has been 
successfully achieved. The distributed generation units DGs have been arranged in order to generate and adequate power to supply the connected loads. The proposed model showed a good energy coordination between the renewable energy sources (islanded mode) as well as in the grid connected mode. Whereas the DGs still able to supply even in the case of grid connected mode. Here one may observe the importance of micro-grid in term of supplying an essential loads or reduce the overall losses in the network. When studying the micro-grid, a large number of power electronics devices are included in the design. This is due to the renewable energy sources such as photovoltaic or the use of fuel cells. In this case a converter is needed to boost and regulate the voltage before either supplying a DC load or converting it into AC power. There are plenty of designs to cater the conversion problem, where the nature of DGs forces this kind of devices to the system. A tremendous amount of harmonics is supplied and introduced to the system due to the use of these power electronic devices [9]: [15]. Plenty of works in the literature have attempted to mitigate the presence of harmonics in the micro-grid or the overall power system. Some works have significantly contributed to the problem as in [16]: [25], where the harmonics have been highly attenuated. There are many studies have been conducted in this regard and yet, the harmonics still considered as a serious issue in power system. The transformation between islanded mode and grid connected mode can cause huge amount of harmonics to be leaked into the system. The analysis of the totl harmonic distortion (THD) has been carried according to IEEE standards, whereas the THD percentage has been kept to the minimum. In this work, the presence of THD was found to be less than $5 \%$ which tallies with the standard.

\section{CONCLUSION}

Micro-grid network with both operation modes (islanded and grid connected mode) have been modelled in this work. Distributed generations with size of $1 \mathrm{M}$ Watt have been designed by using the wind turbine and solar PV system. Furthermore, total harmonic distortion between two operation modes of gridconnected and the islanded-mode have been conducted by the FFT analyzer in order to observe the network power quality stability. According to the IEEE standards system with below than five percent of total harmonic distortion are acceptable to apply. Anyway, the percentage harmonic of islanded MG mode can be minimized by the addition of harmonic active filters. Solar PV and wind turbine generator are types of DG used in this research in order to investigate the implementation process of energy independence and development of renewable energy-efficient and low-emissions technology. There are three phase harmonic filter that consist of four types of filter which is single tuned filter, double tuned filter, high pass filter, c-type high pass filter. Besides that, another component able to support the network performance reliability such as battery storage system complete with charging and discharging control technique.

\section{ACKNOWLEDGEMENT}

The authors would like to express their gratitude to Universiti Kuala Lumpur for supporting and funding this research under grant No. str18005.

\section{REFERENCES}

[1] Jayawarna, N., Wu, X., Zhang, Y. and Jenkins, N. (2006). Stability of a Microgrid Power Electronics, Machines and Drives, The 3rd IET International Conference, 2006 The Contarf Castle, Dublin, Ireland. 316 - 320.

[2] Zoka, Y., Sasaki, H., Yorino, N., Kawahara, K. and Liu, C. C. (2004). An interaction problem of distributed generators installed in a MicroGrid. Electric Utility Deregulation, Restructuring and Power Technologies, 2004. (DRPT 2004). Proc. IEEE Int. Conf., 2004, 795-799.

[3] Thallam, R. S., Suryanarayanan, S., Heydt, G. T. and Ayyanar, R.(2006). Impact of Interconnection of Distributed Generation on Electric Distribution Systems - A Dynamic Simulation Perspective, I Power Engineering Society General Meeting, IEEE Conference 2006, Montreal, Que.

[4] Singh, B., Burman, S.P. (2016). Power Quality (2 ed.). New Delhi: S.K. Kataria \& Sons.

[5] Alotaibi, M., Almutairi, A., \& Salama, M.M. (2016).Effect of wind turbine parameters on optimal DG placement in power distribution system. 2016 IEEE Electrical Power and Energy Conference (EPEC).

[6] Alhamrouni, Ibrahim, Wan Ismail Hanis, Mohamed Salem, Fadi M. Albatsh, and Bazilah Ismail. "Application of DC-DC converter for EV battery charger using PWM technique and hybrid resonant." In Power and Energy (PECon), 2016 IEEE International Conference on, pp. 133-138, 2016.

[7] I Alhamroun, M Salem, A Jusoh, NRN Idris, B Ismail \& FM Albatsh (2017), "Comparison of two and four switches inverter feeding series resonant converter,"”. The 3rd IEEE Conference on Energy Conversion, IEEE-CENCON' 17. At: Kuala Lumpur (Malaysia). 
[8] M Salem, A Jusoh, NRN Idris and I Alhamroun, "Phase-shifted Series Resonant DC-DC Converter for Wide Load Variations Using Variable Frequency Control”. The 3rd IEEE Conference on Energy Conversion, IEEE-CENCON' 17. At: Kuala Lumpur (Malaysia).

[9] I Alhamrouni, MK Rahmat, FA Ismail, M Salem, A Jusoh, T Sutikno. "Design and development of SEPIC DC-DC boost converter for photovoltaic application” Int J Pow Elec \& Dri Syst ISSN 2088 (8694), 8694

[10] Mohamed Salem, Awang Jusoh, N. Rumzi N. Idris, Himadry Shekhar and Ibrahim Alhamrouni, "Resonant power converters with respect to passive storage (LC) elements and control techniques-An overview" June 2018, Renewable and Sustainable Energy Reviews 91(August 2018).

[11] M Salem, A Jusoh, NRN Idris, I Alhamrouni. "Extension of Zero Voltage Switching range for series resonant converter” Energy Conversion (CENCON), 2015 IEEE Conference on, 171-175

[12] M Salem, A Jusoh, NRN Idris, I Alhamrouni “A Review of an Inductive Power Transfer System for EV Battery Charger”, European Journal of Scientific Research 107 (1), 42-56.

[13] M Salem, A Jusoh, NRN Idris, I Alhamrouni. "Modeling and simulation of generalized state space averaging for series resonant converter" 2014 Australasian Universities Power Engineering Conference (AUPEC), 1-5.

[14] I Alhamrouni, MA Hairullah, NS Omar, M Salem, A Jusoh, T Sutikno. "Modelling and design of PID controller for voltage control of AC hybrid micro-grid” Int J Pow Elec \& Dri Syst 10 (1), 151-159.

[15] Dinesh Kumar; Firuz Zare. "Harmonic Analysis of Grid Connected Power Electronic Systems in Low Voltage Distribution Networks" IEEE Journal of Emerging and Selected Topics in Power Electronics. 2016, Vol 4, Issue: 1 Page s: $70-79$.

[16] Iman Askarian; Suzan Eren; Majid Pahlevani ; Andy M. Knight. "Digital Real-Time Harmonic Estimator for Power Converters in Future Micro-Grids". IEEE Transactions on Smart Grid. Year: 2018 , Volume: 9 , Issue: 6, Page s: $6398-6407$.

[17] Fei Wang, Xiayun Feng, Lijun Zhang, Yan Du ; Jianhui Su. "Impedance based analysis of grid harmonic interactions between aggregated flyback micro-inverters and the grid" IET Power Electronics. 2018, Vol: 11, Issue: 3. Page s: $453-459$.

[18] Quoc Nam Trinh ; Peng Wang ; Yi Tang; Fook Hoong Choo. "Mitigation of DC and Harmonic Currents Generated by Voltage Measurement Errors and Grid Voltage Distortions in Transformerless Grid-Connected Inverters". IEEE Transactions on Energy Conversion. Year: 2018, Volume: 33 , Issue: 2. Page s: $801-813$

[19] Cristiano A. G. Marques ; Moisés V. Ribeiro ; Carlos A. Duque ; Paulo. F. Ribeiro ; Eduardo A. B. da Silva. "A Controlled Filtering Method for Estimating Harmonics of Off-Nominal Frequencies" IEEE Transactions on Smart Grid. Year: 2012, Volume: 3 , Issue: 1. Page s: 38 - 49

[20] Fernando Cardoso Melo, Robson Ruiz Spaduto; Luiz Carlos Gomes de Freitas ; Carlos Eduardo Tavares ; Jose Rubens Macedo Jr ; Paulo Henrique Oliveria Rezende. "Harmonic Distortion Analysis in a Low Voltage GridConnected Photovoltaic System". IEEE Latin America Transactions. 2015, Vol 13, Issue: 1. Page s: 136 - 142.

[21] I Alhamrouni, M Salem, A. Jusoh, NRN Idris, B Ismail, FM Albatsh, "Comparison of Two and Four Switches Inverter Feeding Series Resonant Converter”, 2017 IEEE Conference on Energy Conversion (CENCON), 2017.

[22] M Salem, A. Jusoh, NRN Idris, I Alhamrouni, "Comparison of LCL Resonant Converter with Fixed Frequency, and Variable Frequency Controllers” 2017 IEEE Conference on Energy Conversion (CENCON).

[23] Dionisis Voglitsis ; Nick Papanikolaou; Anastasios Ch. Kyritsis. "Incorporation of Harmonic Injection in an Interleaved Flyback Inverter for the Implementation of an Active Anti-Islanding Technique". IEEE Transactions on Power Electronics. 2017 , Vol 32 , Issue: 11. Page s: 8526 - 8543.

[24] Ali Emadi; Hosein Afrakhte; Javad Sadeh. "Fast active islanding detection method based on second harmonic drifting for inverter-based distributed generation". IET Generation, Transmission \& Distribution. Year: 2016, Volume: 10 , Issue: 14. Page s: $3470-3480$.

[25] Haiyu Zhang; Xiao Li ; Shunlong Xiao ; Robert S. Balog. "Hybrid hysteresis current control and low-frequency current harmonics mitigation based on proportional resonant in dc/ac inverter". IET Power Electronics. Year: 2018 , Volume: 11 , Issue: 13. Page s: 2093 - 2101. 